\title{
Unfulfilled farmer expectations: the case of the Insect Resistant Maize for Africa (IRMA) project in Kenya
}

Justin Mabeya ${ }^{1 *}$, Obidimma C Ezezika ${ }^{1,2,3}$

\begin{abstract}
Background: Maize is the most important staple food in Kenya; any reduction in production and yield therefore often becomes a national food security concern. To address the challenge posed by the maize stem borer, the Insect Resistant Maize for Africa (IRMA) agricultural biotechnology public-private partnership (PPP) project was launched in 1999. There were, however, pre-existing concerns regarding the use of genetic engineering in crop production and skepticism about private sector involvement. The purpose of this case study was to understand the role of trust in the IRMA partnership by identifying the challenges to, and practices for, building trust in the project.

Methods: Data were collected by conducting face-to-face, semi-structured interviews; reviewing publicly available project documents; and direct observations. The data were analyzed to generate recurring and emergent themes on how trust is understood and built among the partners in the IRMA project and between the project and the community.

Results: Clear and continued communication with stakeholders is of paramount importance to building trust, especially regarding competition among partners about project management positions; a lack of clarity on ownership of intellectual property rights (IPRs); and the influence of anti-genetic modification (GM) organizations. Awareness creation about IRMA's anticipated products raised the end users' expectations, which were unfulfilled due to failure to deliver Bacillus thuringiensis (Bt)-based products, thereby leading to diminished trust between the project and the community.

Conclusions: Four key issues have been identified from the results of the study. First, the inability to deliver the intended products to the end user diminished stakeholders' trust and interest in the project. Second, full and honest disclosure of information by partners when entering into project agreements is crucial to ensuring progress in a project. Third, engaging stakeholders and creating awareness immediately at the project's inception contributes to trust building. Fourth, public sector goodwill combined with private sector technology and skills are necessary for a successful partnership. These findings may serve as a useful guide for building and fostering trust among partners in other agbiotech PPPs in sub-Saharan Africa.
\end{abstract}

\section{Background}

\section{Maize in Kenya}

Maize is the most important staple food in Kenya with approximately 28 million bags ( 2.5 million tonnes) produced annually while annual consumption is approximately 34 million bags (3.06 million tonnes) [1]. Over $75 \%$ of the maize in Kenya is produced by small-scale

\footnotetext{
* Correspondence: justin.mabeya@srcglobal.org

'Sandra Rotman Centre, University Health Network and University of

Toronto, Toronto, Ontario, Canada

Full list of author information is available at the end of the article
}

farmers who have limited capacity to produce efficiently and in sufficient amounts to meet the nation's needs. Kenya currently supplements its maize shortfalls by importing from its neighboring countries-Uganda and Tanzania-and other international sources [2]. One factor contributing to the shortfalls in maize production in Kenya is attack by the maize stem borer insect pest, which causes a yield loss of $13.5 \%$ [3]. The two most important species of this pest are Buseola fusca and Chilo partellas, both of which account for over $80 \%$ of the yield loss [4]. Management of the maize stem borer in Kenya

\section{(Ciomed Central}


has been done mainly through the use of pesticides such as Bulldock ${ }^{\circledR}$ (a synthetic pyrethroid) [5]. Managing the incidence of the stem borer with pesticides, however, is unaffordable and poses health and environmental risks to small-scale farmers [6].

Another method tried for managing the stem borer in Kenya has been the 'Push and Pull' cropping system developed by the International Centre of Insect Physiology and Ecology (ICIPE) [7]. In this system, the "stem borers are attracted to napier grass (Pennisetum purpureum), which is used as a trap plant (pull), and are repelled from the main cereal crop using a repellent legume intercrop (push), desmodium (Desmodium spp.)" [7]. For further up-scaling this system requires, among other needs, integration with livestock to utilize desmodium and capacity building of the farmers on how to run the system, as well as a more conducive policy framework-factors that may have contributed to slow adoption of the technology by farmers.

\section{History of the Insect Resistant Maize for Africa (IRMA) project}

Based on the aforementioned challenges, the IRMA partnership was formed to develop conventional and transgenic maize varieties resistant to the stem borer. IRMA technologies were expected to reduce farmers' risks of being exposed to pesticides while ensuring effective management of the pest. This would be achieved by transforming farmer-preferred maize varieties using genes extracted from a naturally occurring soil bacterium Bacillus thuringiensis (Bt) [8]. The project aimed to develop varieties yielding $40 \%$ more maize for improved food security and increased household income for maize-growing communities, first in Kenya and then in other African countries [9].

The first efforts leading to the establishment of the IRMA project were initiated before 1997 by members of the International Maize and Wheat Improvement Center (CIMMYT) Board of Trustees. Cognizant of the maize crop losses due to stem borer pests, as well as the difficulties faced by small-scale farmers in managing the pests, the Board requested CIMMYT to develop an African-wide solution to the African maize stem borer. Financial support for the development of a Bt technology to manage the stem borer was sought from the Novartis Foundation, whose then Director, Dr. Klaus Leisinger, was also serving as a member of the CIMMYT Board [9].

After a year of negotiations, Dr. Leisinger secured funding from the Novartis Foundation. To avoid a possible conflict of interest, the Novartis Foundation ensured that their funding was free of Novartis-owned technologies and contingent upon the use of traditional breeding methods complementary to genetic modification (GM) techniques [9].
In 1999, the IRMA project was launched in Kenya with the Kenya Agricultural Research Institute (KARI) and CIMMYT acting as the key implementing partners with funding support from the Novartis Foundation (see Additional file 1 for short profiles of the IRMA project partners). In 2000, the Novartis Foundation and AstraZeneca merged their agribusinesses to form Syngenta [10]. In 2001, the Syngenta Foundation for Sustainable Agriculture (SFSA) was established to replace the Novartis Foundation, with Dr. Leisinger becoming the Acting Executive Director. SFSA continued to fund the IRMA project.

Additional partners, such as the University of Ottawa and Monsanto Company, joined at various phases of the project. The key collaborators (and their contributions) included the Ministry of Agriculture (MoA) for advisory and public awareness, the Kenyan Plant Health Inspectorate Services (KEPHIS) and National Council for Science and Technology (NCST) for regulatory affairs, the University of Ghent for training on regulatory and biosafety issues, and Agriculture Research for Development (CIRAD) of France for synthesis of Bt events for the development of IRMA maize lines. Others included the Africa Biotechnology Stakeholders Forum (ABSF) for communication and awareness creation, and the Rockefeller Foundation for funding.

The partners took up various responsibilities based on their expertise and experience (see Additional file 2 for more details on the partners' responsibilities). KARI hosted new IRMA GM technology testing sites, while CIMMYT and SFSA were responsible for institutional capacity building. The partners' and collaborators' efforts at creating awareness among women and religious associations, consumer organizations, the private sector, various government ministries and maize processors further contributed to the achievement of the project's objectives [11].

\section{Project progress}

The results achieved were linked to specific phases in the project: IRMA I, IRMA II and IRMA III [12]. IRMA I (1999-2003) was the proof of concept stage and focused on infrastructure and personnel development. After five years, the project had achieved:

- The development of source lines of the key Bt genes $C r y 1 A b$ and $C r y 1 B a$, which are effective against the target pests. Source lines are the base material needed to transfer the Bt genes to target maize germplasm in Kenya.

- The establishment of the necessary infrastructure and training of staff in Kenya to allow for the safe handling of Bt maize.

- The identification of local germplasm containing adequate levels of conventional stem borer resistance [12]. 
IRMA II (2004 to 2008) focused on delivering maize germplasm containing conventional and Bt-based insect resistance to Kenyan farmers [12] using the privatesector event MON810 from Monsanto Company [8]. During this phase, the project developed and released conventionally-bred insect-resistant, open-pollinated varieties (OPVs) and hybrids adapted to Kenya's agroecological conditions [12] but failed to deliver Bt-based insect-resistant varieties.

IRMA III (2009 to 2013), which is funded by the SFSA, seeks to "share the benefits from IRMA II to the Eastern and Southern Africa regions" [12]. This phase focuses on developing and deploying conventional maize that is resistant to field and storage insect pests [13]. Bt breeding, which was initially planned [16], is no longer being pursued in phase III.

\section{Trust in agricultural biotechnology}

It has been reported that distrust exists between the public and private partners in agbiotech PPPs. The former views the intentions of the latter with suspicion [14], which often stems from the fear that multinational biotech companies and western countries seek to take advantage of poor nations [15]. The private sector, on the other hand, is skeptical of the public sector's capacity and willingness to change [14]. As a result, competing interests may lead to conflicts that are likely to diminish trust, and which have been identified as an important element hindering the progress of effective PPPs [16]. There is, therefore, a need to appropriately manage factors affecting the establishment, development and maintenance of trust among the partners in agbiotech PPPs to boost the chances of the projects' success. This article presents a descriptive narrative of the findings from our case study of IRMA, particularly as they relate to the dynamics of trust building in agbiotech PPPs.

\section{Methods}

The IRMA project constitutes one of a larger series of eight case studies investigating the role of trust in agbiotech PPPs in Africa. The purpose of this study was to understand the role of trust in the IRMA partnership by:

- describing trust-building practices in the development of the IRMA PPP project;

- describing the challenges associated with trust building in the partnership; and

- determining what makes these practices effective or ineffective.

Data were collected by interviewing eight key informants of the project; conducting a literature review of three relevant project documents and five research articles specific to IRMA; and conducting direct observations. We received Research Ethics Board (REB) approval for conducting the case study from the University Health Network (UHN), University of Toronto before proceeding with the study.
Interviewees were identified first by making a list of key individuals associated with the project based on the stakeholders groups as identified in the research protocol. This list was then populated further through snowball sampling by engaging with stakeholder informants of the Sandra Rotman Centre's Social Audit Project [17]. Through this process a total of 12 potential interviewees were invited for the interview, eight of whom were interviewed. The remaining four were unavailable for various reasons. The potential interviewees were sent an invitation, which included an explanation of the case study series, to participate in the interview. Those who consented to participate were informed that the interview would be digitally recorded, transcribed verbatim and then analyzed.

The interviewees included a farmer and executives from the Cereal Growers Association of Kenya (CGA), CIMMYT, KARI, Simlaw Seeds (SS) and SFSA.

The interviews were conducted in between 2009 and 2010 in Kenya and the United States - at the convenience of the interviewees. The interviews were held faceto-face using a semi-structured interview guide and each lasted approximately one and a half hours. The interview guide included questions on the interviewees' background, their understanding of the project, and their interpretation of the word trust. The interviews further explored the interviewees' perceptions of trust among the partners and with the public, apparent challenges to trust building and observed trust-building practices. Finally, interviewees were asked for their suggestions on how trust in agbiotech PPPs can be improved (see Additional file 3 for sample questions). Using the objectives as theoretical propositions, the data were analyzed by reading through the transcripts and generating recurring and emergent themes. The analysis was completed by reviewing relevant project documents and research articles. All the data were triangulated to create a comprehensive narrative on how trust is understood and built among the partners and with the community. The methods used in this study were adapted from Yin 2003 [18].

\section{Results and discussion}

\section{IRMA partners' understanding of trust}

In order to put into context informants' views with regards to trust, we asked the interviewees to provide their understanding of the word trust. Interviewees considered trust a voluntary and cooperative effort that is achieved, maintained, or destroyed over time based on the perceptions of those involved. Further, trust was thought to be motivated by confidence in the abilities of other people or institutions, agreements, and expectations of positive outcomes based on partner responsibilities. Trust was also described by interviewees to be of varying levels depending on an individual's knowledge of the project and the intended project outcomes. 
Based on interviewees' understanding of trust, and our analysis of the challenges to and practices for trust building, we identified four key lessons that other agbiotech PPPs may find useful for building trust among project partners and with the community. The IRMA management pointed out that they did not deliberately put in place specific practices intended to build trust. Conducting further studies on the effect of deliberate trust-building practices on the success of an agbiotech PPP may therefore be of value. The four key lessons are:

\section{Ensure product delivery}

The commercialization of IRMA products was expected to commence at the end of phase II of the project, with both the transgenic and conventional products becoming available to the public. The interviewees indicated that there were high expectations among the end users for the IRMA products and particularly for the Bt-based maize varieties. Access to the end products would continue to enhance trust among the partners and with the community.

The community disheartened by failure to deliver Bt-based maize varieties

By the end of phase II (ten years from the start of the project), IRMA managed to release conventionally-bred, insect-resistant OPVs and hybrids but failed to deliver the Bt-based insect-resistant maize varieties due to challenges related to ownership of IPRs (see lesson 2) of the Bt technologies. The high expectations among the end users were captured in the views of a farmer interviewed who said that even if the farmers did not have enough information about the technology they would have been happy to adopt the technology once Bt maize varieties came to the market. The same sentiment was echoed by a seed company executive who said that seed companies would have distributed the technology once it came to the market.

In spite of the project management's efforts towards delivering Bt products, skepticism about IRMA's capability to deliver ensued from the project's failure to release the Bt-based maize varieties. The community's-particularly, farmers' and seed companies'-trust in the project, which did not seem to deliver, was therefore undermined.

\section{Concern among the partners about failure to deliver}

The failure to deliver the Bt-based maize varieties was of great concern among the partners. The project management hoped that this problem would be addressed during phase III of the project. However, this may not be realized since phase III places emphasis on further development of conventional varieties [13]. A KARI interviewee expressed the uneasiness and frustration that pervaded the KARI management and government, which had been involved closely with the launch of the KARI Biotechnology Center, where some trials of the Bt technology were conducted. There were concerns among the partners that the project would not deliver the expected biotechnology products after all. The interviewee stated: I would not like to imagine that [the] project will not come out with products. Because people might not trust GM again in Kenya. We observe that failure to deliver the Bt products was likely to result in distrust among the partners and with the community.

\section{Disclose fully information on IPRs}

Considering that agbiotech PPPs rely on technologies protected by IPRs, there is a need for partners to be clear at the start of the project about the ownership status of the IPRs and the manner of their use in order to foster trust among the partners.

\section{Lack of clarity on the ownership of IPRs of the GM event}

One of the most controversial aspects of the IRMA project was perhaps the vagueness surrounding the ownership of IPRs of the GM event. It has been reported that confidentiality and non-disclosure agreements surrounding ownership of IPRs often lead to much suspicion and, in turn, distrust [14]. At the beginning of the project, the Bt genes were sourced from the University of Ottawa based on "a research purposes only" agreement [5]. This was taken to mean that the use of the genes would contribute to building trust between the project and the public-because they were sourced from a public institution. This seemed straight forward until 2006, when the IRMA project management requested the University of Ottawa to enter into an agreement with CIMMYT to enable the latter to commercialize products generated by the project. At this point it was established that the ownership of the different IPR components was in the hands of many private companies, which made it especially difficult for the university to provide a commercialization agreement without facing a potential lawsuit over IPR violations [8]. Interviewees stated that the failure to disclose clearly the IPR status of the technology by the University of Ottawa resulted in diminished trust between the university and the other partners. At the onset of the project, interviewees indicated that the partners engaged in the partnership informally without signed agreements on the presumption that trust existed among them. The agreements were regularized later by making them legally binding. The informality of the initial agreements may have contributed to the lack of clarity on IPRs of the GM event from the University of Ottawa.

\section{Lack of legal expertise}

The late realization that the University of Ottawa did not own the IPRs of the GM event, which was used in phase I of the project, was partly attributed to the inadequate legal advice from both CIMMYT and KARI, since the legal experts from both institutions at the time had left [5]. Meticulous scrutiny of legal agreements to identify any inadequacies that may result in diminished trust among the partners and with the community is very important. However, this requires access to legal expertise within the 
project; otherwise, time and resources will be wasted as the project struggles to deal with legal challenges, including those pertaining to IPRs.

\section{Provide the public with balanced and accurate information}

Public access to balanced, accurate and timely information about the new agricultural biotechnologies is necessary for enhanced trust to exist between the project partners and the public.

\section{The benefits of early and continuous engagement of stakeholders}

In an effort to ensure stakeholders' involvement in the project planning and development, and in response to stakeholders' request to be engaged all along the way, the IRMA management held annual stakeholder meetings; workshops; seminars; and hands-on training sessions with the stakeholders. Other auxiliary activities included the establishment of networks to enhance collaboration with the stakeholders. For example, the Maize and Wheat Working Group in Eastern and Central Africa, which is run by the Association for Strengthening Agricultural Research in Eastern and Central Africa (ASARECA), was organized to address stakeholder issues-from research to market-along the maize and wheat production value chains. Through these networks the stakeholders along the maize value chain were updated with IRMA activities, which helped enhance trust in the project. These activities were part of the project's $10^{\text {th }}$ theme: "Communication, Promotion, Capacity Building, and Administration" [8].

The continuous engagement of different stakeholders with messages tailor-made for them has been heralded as one of the positive aspects of the IRMA project [19]. Early involvement ensured ownership of and commitment to the project and, in turn, built trust among the partners and with the public [15]. Interviewees said that these initiatives enabled expert information on any controversial areas within the project to be passed on to stakeholders, while providing a forum for interaction, feedback and bonding among stakeholders. These activities helped demystify the technology and allay fears surrounding agricultural biotechnology, thus building trust among project partners and with the community.

\section{The challenge of early and continuous awareness creation}

The downside of early and continuous engagement was the high expectations that were formed by the stakeholders but left unmet by the project. An interviewee from CIMMYT acknowledged that the expectations of the stakeholders may have been raised too early in the project's life. We observed the challenge of maintaining a balance between creating awareness among the stakeholders and ensuring that the expectations of the stakeholders are reasonable and not unwarranted. Considering that it takes 10 to 15 years or more to develop GM crops into end products that can be delivered to the farmers [20], the objective to deliver Bt-based varieties at the end of phase II may have been unrealistic. In retrospect, the project management suggested that it was inappropriate to raise expectations about the project prematurely.

Awareness creation should be carefully done to ensure that delayed product delivery neither negatively impacts trust between the partners and the community nor leaves the end users dissatisfied. This requires seeing the big picture and integrating regular evaluation. It has been reported that the peak of awareness creation and stakeholder engagement should wait until the technology is available and farmers are ready to plant [20,21].

\section{Engaging with anti-GM lobbyists to build trust}

Some of the engagement sessions in IRMA were open to anti-GM lobbyists. At times during these sessions, the anti-GM activists were engaged in one-on-one discussions with the project management to clarify any inaccuracies; however, this did not seem to change their position. In some situations, anti-GM organizations took advantage of cases of inadequate public awareness of GM crops to spread negative and inaccurate views about health and other perceived risks associated with the technology for the sole purpose of fostering the public's distrust in the technology. In one particular instance reported by an interviewee from CIMMYT, the anti-GM organizations claimed that GM maize was sneaked into KARI-Kiboko Research Centre, Kenya, which was also an IRMA trial site.

An interviewee from the seed industry attributed limited public awareness partly to the scientists' failure to adequately engage and communicate with the public. He emphasized the need for greater expertise in communications in order to reach the farmers with accurate information on GM technology. An interviewee from CIMMYT reported that IRMA's limited communication with the public was further undermined by the limited ability of the project management to regularly update the public on developments in the project due to funding cuts and the departure of a communications specialist from the project.

An interviewee from KARI suggested that, to counter any inaccuracies due to anti-GM lobbyists' influencing of public opinion, sufficient and accurate information should be provided to the public, rather than having a one-on-one engagement with such groups. This would go a long way in addressing the challenge - since changing the attitude of anti-GM lobbyists is difficult.

\section{Maximize synergy between the public and private sector}

Partners in agbiotech PPPs come from diverse backgrounds and each has their own set of strengths to contribute to the partnership. Capitalizing on the diversity of the partners can help improve trust and the project's success. 


\section{Individual and institutional differences between KARI and CYMMYT}

In a PPP, there is need for roles and responsibilities to be clearly defined for the purpose of creating efficiency and accountability [22]. In some instances this can prove to be challenging, particularly when a partnership cascades down to the community and seeks to engage with members of the community - as was the case in the IRMA project. At that level, coordinating mechanisms are required to ensure efficiency and accountability. The differences between KARI and CIMMYT were reported as having threatened project efficiency, accountability and trust between the two public sector institutions. The differences existed at both an individual and institutional level. At the individual level, the problem stemmed from competition for the position of the project coordinator, while at the institutional level there was a perception of inequality and favoritism among the partners, with KARI feeling that they were being treated as a junior partner. An interviewee from KARI acknowledged that these differences created some conflict.

The interviewees acknowledged that these apparent sources of conflict were resolved over time by establishing well-defined objectives and responsibilities and transparent resource allocation, all of which served as an opportunity for partners to be accountable to each other and to the community. Accountability was partly linked to the mutual pressure-referred to by an interviewee as "peer pressure"-that the partners placed on each other to fulfill their responsibilities. In general, however, instead of competing interests on the part of the partners, their expertise, roles and responsibilities were complimentary and mutually reinforcing for the progress of the project and led to a cordial relationship. This led to enhanced trust and a "highly motivated team" [8], leading to achievement of the project milestones. In addition, agreement on the selection of a project coordinator for the duration of the project gave the partners and their staff a sense of stable leadership, which worked to build trust.

The presence of a local public institution in the partnership also enhanced trust between the partners and the public. This is because the local farming community tends to identify with local public organizations, with which they have built trust from previous engagements. The involvement of such institutions as the face of the project builds public confidence in the quality and safety of the technologies offered by the partnership. Notwithstanding earlier differences with KARI, an interviewee from CIMMYT pointed out that partnering with KARI, a local public research institution, boosted public acceptance of the process and expected products.

\section{Apprehension about the private sector's involvement in the project}

More often than not, distrust in agbiotech PPPs has stemmed from the ownership of IPRs and usually occurs between the private and public institutions [23]. This may explain the public sector's suspicions about the private sector's intentions in a PPP. The public sector partners were apprehensive about the private sector's involvement in technology development even at the beginning of the IRMA project, as they believed such involvement could hamper public support and complicate the funding principle, i.e., the public good of the project.

Some were also of the view that the use of public genes from the University of Ottawa would improve the public's trust in the project. However, according to an interviewee from CIMMYT, when the public sector materials sourced from the University of Ottawa were no longer suitable for commercialization, CIMMYT had to turn to a private sector GM event (MON810) [8] for the project to progress into phase II. The private sector, although seen as inspiring less trust, was deemed valuable in terms of providing technological and skills support when the public sector failed to deliver.

Irrespective of whether an institution is public or private, there is a need for the institutions to find common ground and converge on common interests in the partnership in order to encourage a united focus in the project. Identifying individual and institutional strengths and building synergy between them, and tapping into the goodwill of the local public institutions, is likely to contribute to enhancing trust between the project and the community.

\section{Conclusion}

Africa is experiencing significant growth in the agbiotech field through PPPs. The IRMA PPP project is an example of how the development of agbiotech products in Africa entails several challenges to trust building and how project management can address them and build trust among the partners and with the community. From this study there are at least four aspects that new and ongoing agbiotech projects should put in place for building trust: the partnership should ensure product delivery; disclose fully and honestly all the necessary information including IPRs ownership; share balanced and accurate information with the stakeholders; and maximize the synergy between the public and private sectors.

Farmers in Kenya look forward to the IRMA project to provide an affordable management solution for controlling stem borers with less use of pesticides. Similarly, agbiotech PPP projects in Africa should ensure delivery of end products to the consumers to avoid breaking 
trust between the project and the community. While they do so, they should also ensure that:

- Agreements are carefully scrutinized to eliminate any loopholes and keep partners accountable for their end of the bargain. This is necessary because agreements per se may not be safeguards to trust between the partners;

- The partners carefully engage the public by providing accurate, balanced and timely information so as not to raise unwarranted expectations that may become difficult to manage and;

- Partners should build synergy from the strengths of the various public and private partners so that differences, instead of producing distrust, become cause for trust building. This way trust will be sustained among the partners and with the community.

\section{Additional material}

Additional file 1: Insect Resistant Maize for Africa core partners.

Additional file 2: Responsibilities of the IRMA core partners.

Additional file 3: Sample questions from the interview guide.

\section{Acknowledgments}

The authors are grateful to each of the participants who contributed substantial time and effort to this study. The authors also thank Hassan Massum, Jessica Oh and Jennifer Deadman for comments on earlier drafts of the manuscript.

This project was funded by the Bill \& Melinda Gates Foundation and supported by the Sandra Rotman Centre, an academic centre at the University Health Network and University of Toronto. The findings and conclusions contained within are those of the authors and do not necessarily reflect official positions or policies of the foundation. This article has been published as part of Agriculture \& Food Security Volume 1 Supplement 1, 2012: Fostering innovation through building trust: lessons from agricultural biotechnology partnerships in Africa. The full contents of the supplement are available online at http:/www.agricultureandfoodsecurity.com/ supplements/1/S1. Publication of this supplement was funded by the Sandra Rotman Centre at the University Health Network and the University of Toronto. The supplement was devised by the Sandra Rotman Centre.

\section{Author details}

'Sandra Rotman Centre, University Health Network and University of Toronto, Toronto, Ontario, Canada. ${ }^{2}$ African Centre for Innovation and Leadership Development, Federal Capital Territory, Abuja, Nigeria. ${ }^{3}$ Dalla Lana School of Public Health, University of Toronto, Toronto, Canada.

\section{Authors' contributions}

Study conception and design: OCE and JM. Data collection: JM and OCE. Analysis and interpretation of data: JM and OCE. Draft of the manuscript: JM and OCE. Critical revision of the manuscript for important intellectual content: OCE and JM. All authors read and approved the final manuscript.

\section{Competing interests}

The authors declare that they have no competing interests.

Published: 1 November 2012

\section{References}

1. Kioko A, Cereal Growers Association of Kenya: Maize production and consumption in Kenya. 18th April 2012.
2. Owuor B: The Maize Subsector in Kenya: Mending the Granary: Survey for the Heinrich Böll Foundation Regional Office for East \& Horn of Africa Nairobi, Kenya. 2010.

3. Integrated Approaches to Higher Maize Productivity in the New Millennium. In Proceedings of the Seventh Eastern and Southern Africa Regional Maize Conference: 11-15 February 2002; Nairobi, Kenya. CIMMYT (International Maize and Wheat Improvement Center) and KARI (Kenya Agricultural Research Institute); Friesen DK, Palmer AFE 2004:

4. DeGroote H, Overholt W, Ouma JO, Mugo S: Assessing the potential impact of Bt maize in Kenya using a GIS based model. Proceedings of the International Agricultural Economics Conference: August 2003; Durban 2003.

5. Pest Control Products Board: List of registered pest control products for use in Kenya. 2010.

6. Mugo S, Gichuki S: Taming Major Maize Field Pests in Kenya: The Role of Biotechnology. Presentation to OFAB, Jacaranda Hotel, Nairobi, Kenya 30th July 2009 .

7. Khan Z, Midega C, Pittchar J, Pickett J, Bruce T: Push-pull technology: a conservation agriculture approach for integrated management of insect pests, weeds and soil health in Africa. International Journal of Agricultural Sustainability 2011, 9(1):162-170.

8. KARI, CIMMYT: Insect Resistant Maize for Africa Annual Report 2006. 2006, 27:1-140.

9. Burgi J: Insect Resistant Maize: A case study of fighting the African stem borer. Oxfordshire: CABl; 2009.

10. Syngenta Foundation: Development of Environmentally Safe, Insect Resistant Maize Varieties for Food Security in Kenya. 2010, 1-17.

11. KARI, CIMMYT: Insect Resistant Maize for Africa (IRMA) Updates. 2002, 1-2: 1-6.

12. Mugo SJ, Gethi JO, Ouma S, Ajanga J, Beyene GM, Murenga M, Mulaa P, Likhayo S, Gichuki V, Kega H, De Groote H, Chavangi A: Book of abstract of the "Consolidating Experiences from IRMA I and II: Achievements, Lessons and Prospects.". Proceedings of the IRMA Project End-of-Phase II Conference: 28-30 October 2008; Nairobi Safari Club Hotel, Nairobi, Kenya 2008.

13. International Maize and Wheat Improvement Centre (CIMMYT). [http:// www.cimmyt.org/en/what-we-do/projects-by-region/insect-resistant-maizefor-africa].

14. Spielman DJ, Grebmer K: Public-Private Partnerships in International Agricultural Research: An Analysis of Constraints. Journal of Technology Transfer 2006, 31:391-300

15. Ezezika OC, Daar AS, Barber K, Mabeya J, Thomas F, Deadman J, Wang D, Singer PA: Factors influencing agbiotech adoption and development in sub-Saharan Africa. Nature Biotechnology 2012, 30:38-40.

16. Zheng J, Roehrich JK, Lewis MA: The dynamics of contractual and relational governance: Evidence from long-term public-private procurement arrangements. Journal of Purchasing and Supply Management 2008, 14:43-54.

17. Ezezika OC, Thomas F, Lavery JV, Daar AS, Singer PA: A Social Audit Model for Agro-biotechnology Initiatives in Developing Countries: Accounting for Ethical, Social, Cultural and Commercialization Issues. Journal of Technology Management and Innovation 2009, 4(3):24-33.

18. Yin RK: Case study Research: Design and Methods. California: Sage Publications; 42003.

19. Wangalachi A, Poland D, Mugo S, Gichuki ST, Ouya D, Kimani G, Rabar J: Experiences in effective communication on transgenic technology in Africa - the case of the insect resistant maize for Africa (IRMA) project. African Journal of Biotechnology 2011, 10(23):4694-4698.

20. Eicher CK, Maredia K, Sithole-Niang I: Biotechnology and the African farmer. East Lansing Ml: Department of Agricultural Economics, Michigan State University; 2005.

21. Ezezika O, Mabeya J: How to engage with farmers over GM crops. SciDev Net 2012, Opinion.

22. Barrett D, Austin J, McCarthy S: Cross-Sector Collaboration: Lessons from the International Trachoma Initiative.Anonymous 9 Bow Street Cambridge, Massachusetts 02138 USA 2000.

23. Spielman DJ, Hartwich F, Grebmer K: Public-Private Partnerships in International Agricultural Research. International Food Policy Research Institute; 2007, , 9: 1-6.

doi:10.1186/2048-7010-1-S1-S6

Cite this article as: Mabeya and Ezezika: Unfulfilled farmer expectations: the case of the Insect Resistant Maize for Africa (IRMA) project in Kenya. Agriculture \& Food Security 2012 1(Suppl 1):S6. 